\title{
Molecular evidence for cross boundary spread of Salmonella spp. in meat sold at retail markets in the middle Mekong basin area
}

\author{
Dethaloun Meunsene ${ }^{1}$, Thanaporn Eiamsam-ang ${ }^{1}$, Prapas Patchanee ${ }^{2}$, Ben Pascoe $^{3}$, Phacharaporn Tadee ${ }^{4}$, \\ Pakpoom Tadee ${ }^{\text {Corresp. } 2}$ \\ ${ }^{1}$ Graduate Program in Veterinary Science, Faculty of Veterinary Medicine, Chiang Mai University, Muang, Chiang Mai, Thailand \\ 2 Integrative Research Center for Veterinary Preventive Medicine, Faculty of Veterinary Medicine, Chiang Mai University, Muang, Chiang Mai, Thailand \\ 3 The Milner Centre for Evolution, University of Bath, Claverton Down, Bath, United Kingdom \\ 4 Faculty of Animal Science and Technology, Maejo University, San Sai, Chiang Mai, Thailand \\ Corresponding Author: Pakpoom Tadee \\ Email address: pakpoom.t@cmu.ac.th
}

Background: The surrounding areas of the middle Mekong basin , particularly along the border between Thailand and Lao People's Democratic Republic (Lao PDR), are high-risk areas for many livestock-associated foodborne illnesses, especially salmonellosis. This study aimed to determine the prevalence and characteristics of Salmonella spp.

contamination in pork, beef and chicken meats sold at retail markets in the Thailand-Laos border area surrounding the Thai-Lao Friendship Bridge I from January to May 2019. We focused on the prevalent serotypes, antimicrobial susceptibility profiles and the multilocus sequence type (MLST) genotypes of the collected Salmonella strains. Results: From a total of 370 meat samples collected, $63 \%$ were positive for Salmonella, with the prevalence of $73 \%, 60 \%$ and $56 \%$ from pork, beef and chicken meat samples, respectively. Of all the positive samples, 53 serotypes were identified. Of these, Salmonella enterica serovar London accounted for the majority (27\%), followed by serovars Corvallis (14\%), and Rissen (6\%). Resistance against tetracycline was found at the highest frequency (50\%), followed by ampicillin (35\%) and sulfamethoxazole-trimethoprim (28\%). MLST revealed no evidence of shared genetic relatedness of Salmonella at retail sites among Thailand-Laos border zone. However, a diverse range of Salmonella genotypes were spread over the area. Besides, the persistence of the residential pathogen and sharing of the supply route within-country can be inferred. Conclusions: Given the high levels of contamination of retail meats, regular disinfecting of all working areas and quality control checking at pre-retail stage must be applied to reduce the transmission of Salmonella and other foodborne pathogens to consumers. The findings of this study will make a significant contribution to the current understanding of Salmonella epidemiology to enhance food 
1 Molecular evidence for cross boundary spread of Salmonella spp. in meat sold at retail

2 markets in the middle Mekong basin area

4 Dethaloun Meunsene ${ }^{1}$, Thanaporn Eiamsam-ang ${ }^{1}$, Prapas Patchanee ${ }^{2}$, Ben Pascoe ${ }^{2,3}$,

5 Phacharaporn Tadee ${ }^{4}$, Pakpoom Tadee ${ }^{2 *}$

6

$7 \quad{ }^{1}$ Graduate Program in Veterinary Science, Faculty of Veterinary Medicine, Chiang Mai

8 University, Chiang Mai, 50100, Thailand

$9 \quad$ Integrative Research Center for Veterinary Preventive Medicine, Faculty of Veterinary

Medicine, Chiang Mai University, Chiang Mai, 50100, Thailand

${ }^{3}$ The Milner Centre for Evolution, University of Bath, Claverton Down, Bath, BA2 7AY, United

12

\section{* Corresponding author: Pakpoom Tadee}

Integrative research center for Veterinary Preventive Medicine, Faculty of Veterinary Medicine, Chiang Mai University, Mae Hia, Muang, Chiang Mai, 50100, THAILAND. Tel: +66 53

948023, Fax:+66 53 948062, E-mail:pakpoom.t@cmu.ac.th 


\section{Abstract}

Background: The surrounding areas of the middle Mekong basin, particularly along the border many livestock-associated foodborne illnesses, especially salmonellosis. This study aimed to determine the prevalence and characteristics of Salmonella spp. contamination in pork, beef and chicken meats sold at retail markets in the Thailand-Laos border area surrounding the Thai-Lao Friendship Bridge I from January to May 2019. We focused on the prevalent serotypes, antimicrobial susceptibility profiles and the multilocus sequence type (MLST) genotypes of the collected Salmonella strains.

Results: From a total of 370 meat samples collected, 63\% were positive for Salmonella, with the prevalence of $73 \%, 60 \%$ and $56 \%$ from pork, beef and chicken meat samples, respectively. Of all the positive samples, 53 serotypes were identified. Of these, Salmonella enterica serovar London accounted for the majority (27\%), followed by serovars Corvallis (14\%), and Rissen (6\%). Resistance against tetracycline was found at the highest frequency $(50 \%)$, followed by ampicillin (35\%) and sulfamethoxazole-trimethoprim (28\%). MLST revealed no evidence of shared genetic relatedness of Salmonella at retail sites among Thailand-Laos border zone. However, a diverse range of Salmonella genotypes were spread over the area. Besides, the persistence of the residential pathogen and sharing of the supply route within-country can be inferred. working areas and quality control checking at pre-retail stage must be applied to reduce the transmission of Salmonella and other foodborne pathogens to consumers. The findings of this 
47 study will make a significant contribution to the current understanding of Salmonella

48

49 epidemiology to enhance food security in the region.

Keywords: Salmonella; retail market; serotype; antimicrobial resistant; MLST; Thailand-Laos border; middle Mekong basin

\section{Introduction}

Salmonella spp. is a significant causative agent of bacterial foodborne illnesses in humans and can be found worldwide (Sirichote et al., 2010; Van Boxstael et al., 2012; Basler et al., 2016). Annually, ninety million cases resulting in 150,000 deaths among salmonellosis patients have been recorded (Campioni et al., 2012). Along with the direct effects Salmonella spp. have on the gastrointestinal tract, evidence of drug resistance is also a major public health concern (Foley \& Lynne, 2008; Kurtz et al., 2017; Jajere, 2019). This can result in a reduction in the effectiveness of first line empirical treatments and limit treatment choices (Van Boxstael et al., 2012). Livestock products (farm animal-origin food), especially meats, are an important source of human salmonellosis (Heyndrickx et al., 2002; Mainali et al., 2009; Rostagno \& Callaway, 2012). Retail markets have been identified as the most significant point of contact for salmonellosis exposure and transmission among humans (Hauser et al., 2011; Gomes-Neves et al., 2012). Improper management and biosecurity during the production process, such as on farms or in slaughterhouses also contribute to the risk of increased pathogen loads in retail meats. Contamination can occur directly or through contaminated equipment due to improper handling practices or unsuitable storage conditions (Lo Fo Wong et al., 2002).

Increased demand for meat consumption has led to an intensive transformation of the animal production industry (Guardabassi et al., 2008). Good Management Practices (GMP) must be 
implemented at all production levels to ensure food safety for consumers. However, these practices are difficult to implement in developing regions, such as the middle Mekong basin and the surrounding areas, particularly along the border between Thailand and Lao People's Democratic Republic (Lao PDR). Animal farming practices are predominantly traditional freerange and smallholder backyard systems, which often employ the minimum hygienic sanitation systems. Moreover, inadequate practices in slaughterhouses and retail outlets, such as on-floor slaughtering and uncontrolled storage conditions in purchasing areas are not ideal practices. Cultural preferences and a lack of awareness among local people about raw meat consumption, in addition to an absence of reliable and high-quality resources, such as clean water and cooking supplies are also important risk factors to be considered (Wilson, 2007; Conlan et al., 2014; Okello et al., 2017). Taken together, these risk factors increase the opportunity for several foodborne diseases, including salmonellosis (Mughini-Gras et al., 2014; Ferrari et al., 2019).

Increased population density strongly correlates with the risk of infectious disease, exponentially (Wilkinson et al., 2018). Large scale population movement in specific geographical areas provide a pathway for disseminating and continuing to shape the epidemic of cross boundary disease (Muñoz-Ramirez et al., 2021). Volume, speed and reach of the movements have been considered as the potent force contribution (Wilson, 1995). In 1994, the Thai-Lao Friendship Bridge I linking Nong Khai Province, Thailand and the Vientiane Capital of Lao PDR was officially opened. More than three million people cross the bridge each year (Australian Embassy, Thailand, 2011). These people cross by way of private and public vehicles to engage in trade and exchange various products. Therefore, the chances of pathogen transmissions between borderline communities are likely to be high. 
92 In a study of Salmonella prevalence in the meat being sold around the Thailand-Laos border

93 region, Sinwat et al., (2016) reported that the prevalence of pork contamination in border areas of

94 Thailand and Laos PDR was 65\%. Moreover, Boonmar et al., (2013) reported that the prevalence

95 of contaminated pork and beef in southern-Laos PDR was 93\% and 82\%, respectively. Both

96 studies reported a widespread variety of serotype distribution including $S$. Typhimurium, $S$.

97 Derby, $S$. Anatum and S. Rissen. Interestingly, almost all strains of Salmonella are currently

98 classified as multidrug-resistant strains. However, based on the data that has been studied, there

99 is an evident lack of reporting information on poultry meat, while it is well known that poultry

100 meat is commonly consumed in this area. Additionally, to gain access to in-depth

101 epidemiological information, a study of the pathogen characteristics at the genetic level should

102 be fulfilled to expand upon the scope of epidemiological knowledge of these pathogens.

103 Multilocus sequence typing (MLST) technique is one of the methods employed in our study.

104 This technique relies on a comparison of the sequences of allele types in a specific group for

105 each set of house-keeping gene and focuses on the genetics to assemble data of the sequence type

106 (ST). The resulting findings can be compared with the information of various databases related

107 to the study of the global bacterial dynamic distribution and their genetic evolution (Liu et al.,

108 2011; Patchanee et al., 2017; Zhou et al., 2020).

109 The purpose of the study was to investigate the prevalence of Salmonella in meat sold at retail

110 markets in the middle Mekong Basin area along the border of Thailand and Lao PDR,

111 surrounding the Thai-Lao Friendship Bridge I. We compared strain serotypes, genotypes and

112 their antimicrobial-resistance patterns and identified genetic and phenotypic variation in

113 Salmonella strains. Understandings of the local population structure, their characteristics and the 114 transmission dynamics of the pathogen will inform regional knowledge gaps in the epidemiology 
115 and form the basis for appropriate treatment options as well as preventive measures to help

116 control the spread of human salmonellosis in the region.

117

118 Materials and methods

119 Overview of experimental program

120 A schematic diagram of workflow with laboratory procedure used in this study was displayed in 121 Fig. 1.

122 Source and sample size determination: Marketplaces were purposively selected. All meat for 123 consumption including pork, chicken, and beef samples were randomly collected in aseptic 124 manipulation.

125 Sample collection: All meat samples were sampled and labeled in the purchasing process.

126 Collector immediately placed each sample in cooler box and transported it to the laboratory 127 within 24 hours after collection.

128 Laboratory procedure: Salmonella spp. was detected based on the ISO-6579 standard method.

129 All Salmonella positive samples were then serotyped and antimicrobial susceptible tested.

130 Selected Salmonella strains were further analyzed by MLST, and phylogenetic tree analysis was

131 finally constructed.

132

133 Sample collection procedures

134 The sample size of this study was determined using the Win Epi online program

135 (http://www.winepi.net/uk/index.htm). The prevalence rates identified in previous studies of 136 65\% (Sinwat et al., 2016), 73\% (Trongjit et al., 2017) and 82\% (Boonmar et al., 2013) were

137 chosen as the "expected prevalence" to calculate the sample sizes for pork, chicken and beef, 
138 respectively. An accepted error rate of $8.5 \%$ and $95 \%$ confidence levels were selected for the

139 required feature inputs. For an infinite population, a minimum of 121, 105 and 79 samples of

140 pork, chicken and beef were designated, respectively. However, in order to achieve greater levels

141 of accuracy and reliability, additional samples were carefully chosen.

142 During the period of January to May 2019, 370 samples (121, 133 and 116 samples of pork, 143 chicken and beef, respectively), approximated of $200 \mathrm{~g} / \mathrm{each}$, were purchased from five retail 144 markets in Vientiane Capital, Lao PDR and six retail markets in Nong Khai Province, Thailand.

145 All targeted markets were selected by convenience sampling. Map of the locations generated by 146 https://www.google.com/maps was displayed in Fig. 2. All samples were individually labeled,

147 put into plastic packs and stored in an icebox for laboratory analysis within $24 \mathrm{hr}$ at the

148 Department of Veterinary Medicine, Faculty of Agriculture, National University of Laos, 149 Nabong Campus, Lao PDR.

\section{Salmonella isolation and identification}

152 Isolation and identification of Salmonella spp. from meat samples (pork, chicken, beef) were performed following ISO6579: 2002 Amendment 1:2007, Annex D technique. Accordingly, $25 \mathrm{~g}$ of samples were enriched with $225 \mathrm{ml}$ of Buffered Peptone Water (BPW; Merck, Germany). The mixing materials were homogenized for $120 \mathrm{sec}$ and incubated at $37^{\circ} \mathrm{C}$ for $24 \mathrm{hr}$. An aliquot of $100 \mu \mathrm{l}$ of the pre-enriched inoculum was transferred to $10 \mathrm{ml}$ of Rappaport-Vassiliadis broth

157 (RV; Oxoid, UK) at $42^{\circ} \mathrm{C}$ for an incubation period of $24 \mathrm{hr}$. The likely colonies were then streaked on Xylose-Lysine-Desocholate agar (XLD; Oxoid, UK) and Brilliant-green Phenol Red Lactose sucrose agar (BPLS; Merck, Germany). After an incubation period of $24 \mathrm{hr}$ at $37^{\circ} \mathrm{C}$, the presumptive colonies were then placed on Triple Sugar Iron agar (TSI; Oxoid, England), urease 
161 and Motility Indole-Lysine agar (MIL; Merck, Germany) for bio-chemical confirmation. An

162 analysis of the strains indicated a correct bio-chemical reaction as positive for Salmonella.

163 Finally, all results were then recorded.

164

165 Serotyping and Antimicrobial susceptibility testing

166 All detected Salmonella spp. specimens were serotyped using the serum-agglutination test 167 according to the White-Kauffmann-Le Minor scheme (Popoff et al., 1993), and were also run

168 through antimicrobial susceptibility testing with agar disk diffusion using ten panels of 169 antimicrobial agents. Amoxicillin-clavulanic acid (AMC) 20/10 $\mu \mathrm{g}$, ampicillin (AMP) $10 \mu \mathrm{g}$,

170 chloramphenicol (C) $30 \mu \mathrm{g}$, ciprofloxacin (CIP) $5 \mu \mathrm{g}$, cefotaxime (CTX) $30 \mu \mathrm{g}$, nalidixic acid

171 (NA) $30 \mu \mathrm{g}$, norfloxacin (NOR) $10 \mu \mathrm{g}$, streptomycin (S) $10 \mu \mathrm{g}$, sulfamethoxazole-trimethoprim

172 (SXT) 23.75/1.25 $\mu \mathrm{g}$ and tetracycline (TE) $30 \mu \mathrm{g}$ (CLSI, 2011) were included. Strains that

173 existed with intermediate resistance were grouped as being susceptible in order to avoid

174 overestimation. Strains that resisted $\geq 3$ of the antimicrobial agents were considered multidrug175 resistant.

176

\section{Multilocus sequence typing (MLST)}

178 Randomly selected 38 specimens of Salmonella obtained from the most frequently found 179 serotypes were genotyped using the MLST technique. DNA was extracted according to the 180 protocol described by Liu et al., (2011). Seven housekeeping genes, including aroC (chorismate 181 synthase); dna N (DNA polymerase III beta subunit); hemD (uroporphyrinogenIII cosynthase);

182 purE (phosphoribosylaminoimidazole carboxylase); sucA (alpha ketoglutarate dehydrogenase); 183 his $\mathrm{D}$ (histidinol dehydrogenase) and thrA (aspartokinase I/homoserine dehydrogenase), were 
184 selected for MLST profiling (REF). PCR amplification of all 7 genes was accomplished using 185 the method previously described by Kotetishvili et al., (2002). In brief, the PCR amplification 186 conditions were $94^{\circ} \mathrm{C}$ for $5 \mathrm{~min}$, followed by 35 amplification cycles, each consisting of 187 sequential incubation at $94^{\circ} \mathrm{C}(45 \mathrm{~s}), 55^{\circ} \mathrm{C}(45 \mathrm{~s})$, and $72^{\circ} \mathrm{C}(5 \mathrm{~min})$. Subsequently, the products 188 were sent to be sequenced at the Macrogen Service Center, Republic of Korea.

189 The sequences obtained in each gene (Supplementary file 1 and Table S1) were transformed 190 into allele numbers, and were compiled according to the sequence type (ST) data obtained from 191 the http://enterobase.warwick.ac.uk/species/senterica/allele_st_search database. Finally, all data 192 of the Salmonella strains acquired from this study were analysed. A phylogenetic tree was constructed using Bionumerics ${ }^{\circledR}$ software version 7.6 (Applied Maths, Belgium).

\section{Statistical analysis}

Salmonella prevalence with their 95\% confidence level were determined by descriptive statistical 197 analysis. The comparison of Salmonella positive proportion among their relevant specifications (location or meat type) were considered using fisher's exact test. Epi Info ${ }^{\mathrm{TM}}$ version 7 completed all analyses. Statistically significant levels were determined at $\mathrm{p}<0.05$.

200

201

\section{Results}

202

A total of 370 raw meat samples were collected on 13 sampling days over a period of 5 months. This included 135 samples from six retail markets in Nong Khai Province, Thailand and a further 235 samples from five retail markets in Vientiane Capital, Lao PDR. Samples were collected from three different types of meat, composed of samples from pork $(n=121)$, chicken $(n=133)$ 206 and beef $(n=116)$. 
207 The overall prevalence of Salmonella spp. was found to be $62.70 \%$ (232/370; 95\% CI: 57.67-

208 67.48\%). Prevalence rates were significantly higher in the samples collected from Laos PDR

$209(70.21 \% ; 165 / 235)$ compared to those collected from the Thai sampling sites $(49.63 \% ; 67 / 135)$

210 ( $<<0.05)$. Salmonella spp. prevalence was highest in pork $(72.73 \% ; 88 / 121)$ compared to chicken

$211(55.64 \% ; 74 / 133)$ and beef $(60.34 \% ; 70 / 116)$. The higher rate samples recovered from pork was

212 statistically significant when compared to those recovered from chicken meats $(\mathrm{p}<0.05)$, but

213 there was less confidence in differences in sample recovery from beef $(p=0.05)$. Table 1

214 demonstrates the distribution details of Salmonella spp. positives with $95 \%$ confidence intervals

215 among the different locations and sample types.

216 In total, 53 Salmonella spp. serotypes were identified by serum-agglutination according to the

217 White-Kauffmann-Le Minor scheme (Table 2). The most common serotypes were $S$. London

218 (26.99\%; 61/232), followed by $S$. Corvallis (13.79\%; 32/232), $S$. Rissen $(6.47 \% ; 15 / 232)$ and $S$.

219 Weltevreden $(6.03 \% ; 14 / 232)$, respectively. These four serotypes were common in both

220 countries, with the exception of $S$. London which was only identified twice in the Thai samples.

221 Stratifying for each meat type, $S$. London was the most common serotype detected from the pork

$222(n=34)$ and beef samples $(n=26)$. For the chicken samples, the highest degree of frequency was

223 found for $S$. Corvallis ( $n=27)$. Interestingly, there were just four serotypes, $S$. London, $S$. Rissen,

$224 S$. Corvallis and $S$. Typhimurium, that were distributed among all meat types.

225 All 232 Salmonella strains were submitted for antimicrobial susceptibility testing. Consequently,

22676 of them $(32.75 \%)$ were classified as multidrug resistant strains. Resistance to tetracycline

$227(49.57 \% ; 115 / 232)$ was found in the highest frequency, followed by ampicillin $(35.34 \% ; 82 / 232)$,

228 and sulfamethoxazole-trimethoprim (28.45\%; 66/232), respectively. On the other hand, 94

229 strains $(40.52 \%)$ were found to be susceptible to all of the tested antimicrobials. Additionally, 
230 only 3 strains $(1.29 \%)$ were found to be resistant to cefotaxime, while $5(2.16 \%)$ and $6(2.59 \%)$

231 strains were found to be resistant to norfloxacin and ciprofloxacin, respectively. In Laos PDR,

232 rates of resistance were also highest against tetracycline $(57.78 \%$; 95/165), ampicillin $(34.55 \%$;

$23357 / 165)$ and sulfamethoxazole-trimethoprim (32.12\%; 53/165). In Thailand, the resistant rates

234 were ranked as follows; ampicillin $(37.31 \% ; 25 / 67)$, tetracycline $(29.85 \% ; 20 / 67)$ and

235 streptomycin $(20.90 \%$; 14/67) (Fig. 3). Resistance rates differed between meat sources,

236 especially in the most effective antimicrobials, for instance almost all strains that were resistant

237 against norfloxacin or ciprofloxacin were from chicken meat (Fig. 3). Thus related with the

238 individual data, there were three strain resisted at least seven antimicrobials test (TCH69: AMP /

239 AMC / CIP / NA / NOR / SXT / TE, TCH44: AMP / AMC / C / CIP / NA / NOR / SXT / TE and

240 TCH32: AMP / AMC / C / CIP / NA / NOR / S / SXT / TE) (Table S2), all three were isolated

241 from Nong Khai, Thailand.

242 Fig. 4 demonstrated the genetic relatedness of Salmonella currently being detected at the

243 Thailand-Laos border area. From the 38 Salmonella strains analysed, 35 genetic characters were

244 found. Many of the strains $(n=28)$ could not be assigned to a known ST and 11 of them could not

245 be grouped in any previously identified ST- clonal complex. One to five variations of

246 housekeeping genes of those 28 un-identifies from known ST were displayed in Table 3. For

247 example, in the details, strain LPO12 with the closest of ST155 sequence type demonstrated the

248 variation of purE gene to the allelic number 706. Besides, strain LCH50 with the closest of

249 ST469 demonstrated the variation of his D and purE to the allelic number of 985 and 84,

250 respectively. The However, for the 7 known STs (ST64, ST155, ST365, ST469, ST516, ST1541,

251 ST5706), four of those (ST64, ST516, ST1541, ST5706) were distinct to a single strain.

252 Nonetheless, two strains were grouped in the ST155, ST365 and ST 469. From the displayed in 
253 Fig. 4, strains grouped in ST155 were derived from a Lao-Aussi market, one (LCH18; 16 Mar)

254 was chicken meat and the another (LPO42; 8 Apr) was pork. Two strains of ST365 originated

255 from Phonsavang market, one (LCH23; 16 Mar) was chicken and the another (LB58; 20 May)

256 was beef were also identified. Additionally, the strains grouped in ST469 were originated from

257 pork (LPO01; 2 May) and beef (LB29; 16 Mar) samples collected from different markets located

258 in nearby areas.

259

260

Discussion

261 The findings obtained from this study represent scientific information on the burden and intensity of Salmonella in livestock meats in a $30 \mathrm{~km}$ radius surrounding the Thai-Lao Friendship Bridge I (Fig. 2). It is well known that this bridge is the primary place for the expansion of trade that has occurred along the Thailand and Laos PDR border since 1994. Overall, prevalence of Salmonella spp. in all sampled meat were found to be $63 \%$. Pork had the highest prevalence (73\%), followed by beef $(60 \%)$ and just over half of the chicken meats $(56 \%)$ tested were contaminated with Salmonella (Table1). Contamination of pork was higher than previously observed in a similar study by Sinwat et al., (2016), where 65\% (95\% CI: 59.26-70.47\%) of pork were contaminated. However, for beef samples the degree of prevalence in this study was lower than the results of a study conducted by Boonmar et al., (2013), in which the prevalence was recorded at $82 \%$ (95\% CI: $58.97-93.81 \%)$. No studies have reported on the prevalence of Salmonella contamination in chicken meats sold in this region. A study conducted by Trongjit et al., (2017) reported on the degree of prevalence of Salmonella infection at the Thai-Cambodia

274 border, which was found to be $73.43 \%$ (95\% CI: 66.65-79.42\%), which is higher than our

275 observed results. In general, most studies have not demonstrated much difference when reporting 
276 numbers, which has been proven by an overlap in the $95 \%$ confidence intervals. Variations in the

277 results might depend upon the time period of the sampling along with any existing geographical

278 factors. Nevertheless, high levels of Salmonella contamination still persist, even though some

279 intervention has been implemented in some of these areas. Salmonella remains a problem in the

280 meat being sold in this region, which has been an important public health concern for the last

281 half decade.

282 The samples isolated from meat sold in Laos PDR were statistically and significantly higher than

283 those isolated over the border in Thailand (Table 1). Normally, sanitation practices are different

284 at each location. In fact, there is no supermarket in Laos DPR. All fresh food, such as meat, can

285 only be bought from fresh markets and mini-grocery stores. The lack of covering materials,

286 unsuitable storage conditions and inadequate disinfection practices at the purchasing areas during

287 the meat cutting and handling processes can substantially increase the risk of bacterial

288 colonization (Gomes-Neves et al., 2012; Patchanee et al., 2016). In Thailand, supermarkets are

289 the preferred place to purchase meat. One-sixth of the Thai samples collected in our study were

290 obtained from supermarkets. Supermarkets provide stringent regulation of their facilities and

291 implement biosecurity and hygiene policies along with quality control practices at the pre-

292 harvesting and harvesting stages along the supply chain. However, in general, standard protocols

293 for every type of retail outlet (supermarkets, mini-grocery stores and fresh markets) tend to be

294 higher in larger cities (Trongjit et al., 2017).

295 With a focus on meat type, pork was found to be the most prevalent when compared with the

296 other types of meat. The reason for this may not be clear. It could be due to the high bacterial

297 loads that emerge during previous production stages, which can then lead to instances of

298 contamination at retail outlets. According to the information obtained from previous studies, 
299 Salmonella prevalence at pig farms and during pig slaughtering processes was higher than in

300 chicken and beef production (Padungtod \& Kaneene, 2006; Trongjit et al., 2017; Phongaran et

301 al., 2019). Another possible explanation for this is that pork is the most common type of meat

302 consumed in this region (Napasirth \& Napasirth, 2018). The amount of dressing required, along

303 with any other forms of manipulation before meat is sold, would likely increase the opportunity

304 for contamination or re-contamination by product exposure at the final.

305 Based on the findings of previous studies, $S$. Typhimurium and $S$. Rissen are the majority

306 serotypes identified in pork (Patchanee et al., 2016; Sinwat et al., 2016). For chicken meat, $S$.

307 Corvallis and $S$. Enteritidis are known to be the dominant serotypes (Trongjit et al., 2017).

308 Additionally, $S$. Stanley and $S$. Typhimurium have been reported as the most commonly recorded

309 serotypes in beef (Boonmar et al., 2013). At the moment, these serotypes have not been

310 universally matched to each meat type, but low frequencies were recorded in some instances.

311 However, $S$. Corvallis is still noted as being the dominant serotype in chicken meat (Table 2).

312 Consequently, new typical sero-characteristics for this region should be set for pork and beef. As

313 the data indicates, $S$. London is presently the most common serotype. Furthermore, several

314 serotypes have been detected, such as $S$. Altona, $S$. Cerro, $S$. Elisabethville, $S$. Itami, $S$.

315 Mikamasima, S. Ruzizi, etc. They have been reported for the very first time about the isolation of

316 Salmonella in the region. Time factor and sample picking and the cross-contamination that

317 occurs from other sources, are notable factors. Furthermore, even though the same serotype

318 might be presented at several meat origins, it cannot be concluded that two or three meat types

319 would represent a sharing pool for Salmonella identified from similar sources (Sinwat et al.,

320 2016). All of which would need to be proven. 
321 Salmonella specimens isolated in this study display a relatively high frequency of resistance

322 against tetracycline and ampicillin (Fig. 3), which is consistent with the findings of previous

323 investigations in the region (Padungtod \& Kaneene, 2006; Pulsrikarn et al., 2012; Boonmar et

324 al., 2013). From the past until now, the antimicrobials have been widely used for treatment and

325 prophylaxis in livestock. However, excessive or inappropriate use is considered to be a critical

326 factor that has led to the current situation of resistance (Jajere, 2019). On the contrary, low

327 resistance rates have been recorded for cefotaxime, norfloxacin and ciprofloxacin. Instances of

328 resistance to these antimicrobials are particularly important as these are the drugs of choice for

329 treatment of human salmonellosis. Specifically, quinolones (norfloxacin and ciprofloxacin) are

330 now often used as the first line of treatment (Kurtz et al., 2017). All quinolone-resistant strains

331 isolated in these study areas originated from chicken meat collected in Thailand, and all were

332 found to be resistant to 7-9 of the tested antimicrobials. Selective pressures such as those

associated with antimicrobial use, unsuitable temperatures or $\mathrm{pH}$ levels, could be considered sub-

334 lethal stress factors during the short production cycle in broiler farms. Additionally, the

characterizing of bacterial community composition in chicken's gut should be taken to determine

336 the mechanisms of action on the resistome (Shang et al., 2018; Yang et al., 2019).

337 The strains isolated in this study were genetically diverse and five-sixths could not be assigned to

338 a previously described ST. Regional diversity following microevolution or mutation is a possible

339 explanation for the finding (Harbottle et al., 2006; Liu et al., 2011). Variation in 3-5 of the

340 housekeeping genes used to determine ST was also observed (Table 3), meaning that those

341 strains could not be assigned to any clonal complex either. Large scale, shared genetic

342 relatedness of Salmonella strains isolated along the Thai-Lao border was not observed (Fig. 4).

343 The finding infers that the transboundary food supply chain from locations ahead of the 
344 marketplace (farm and/or slaughterhouse) is not involved in contamination. A larger scale

345 analysis, including all strains previously collected in the region and deposited in MLST

346 databases would help identify additional shared reservoirs of contamination that may have been

347 missed in our study.

348 Salmonella genotypes isolated from a single market also demonstrated high levels of diversity,

349 nine and six Salmonella genotypes were isolated from various meat types in markets from

350 Phonsavang and Chengsavang, respectively. This suggests that more than one infection source

351 can exist at a given location. Contamination can occur by itself in the purchasing area or as a

352 result of inadequate processing when the meat product may have already been contaminated.

353 Unhygienic practices at previous production sites, such as on farms and at slaughterhouses, or at

354 transportation hubs may increase transmission (Heyndrickx et al., 2002; Campioni et al., 2012).

355 Clones of sequence types ST155 and ST365 were detected on different sampling dates from the

356 same marketplaces, indicative of persistent or residential Salmonella contamination.

357 Additionally, two strains of ST469 were recovered from different markets in nearby areas,

358 hinting at potential shared supply routes and their role in dissemination of Salmonella.

\section{Conclusions}

361 This is the first comprehensive study for the transmission dynamics of Salmonella in Thailand-

362 Lao DPR border area. Multi Locus Sequence Typing (MLST) analysis could eventually serve to 363 pinpoint the genotypic characterization differences and provide more crucial information than

364 other previous studies such prevalence study and phenotypic description. It has been successful

365 for the characterization of clonal relationship among Salmonella circulating in meat sold in the

366 middle Mekong basin area. To the best of our knowledge, there is no molecular evidence of 
367 transboundary epidemiological link among these MLST sequence types. The findings obtained

368 from the study indicate that extensive quality control checking at pre-retail stages should be

369 strictly implemented. Likewise, regular disinfecting of all equipment, as well as at working

370 areas, must be applied. Salmonella's presence was relatively high in terms of prevalence and

371 highlight multidrug resistant for one-third of them. Standard hygienic protocols and integrating

372 of knowledge/attitude/practices in antimicrobial using are known to be maintained at a higher

373 level in administrative areas. However, to expand the epidemiological knowledge of the

374 pathogen, analysis of the Salmonella genetics together with the geographic matching-strains

375 submitted in MLST database should be completed for the further whole genome sequencing

376 study. Finally, future efforts in strengthening food safety education and awareness programs

377 would help authorities to establish strategies that could potentially reduce the transmission of

378 Salmonella and other foodborne pathogens to downstream consumers.

Acknowledgements

381 This study was financially supported by the Faculty of Veterinary Medicine, Chiang Mai

382 University (Project ID: CMU-MIS R000017502). The authors would like to thank the

Bacteriology Section, Veterinary Research and Development Center (Upper Northern Region), Lampang, Thailand and the Vientiane Capital Agriculture and Forestry Department, Vientiane, Laos PDR for their valuable contributions. We would like to thank the Department of Veterinary Medicine, Faculty of Agriculture, National University of Laos for allowing us to use their laboratory facilities for the purposes of diagnosis. Finally, we would like to thank the people who operate the http://enterobase.warwick.ac.uk/species/senterica/allele_st_search website which

389 made our regional analysis possible. 
Disclosure Statement

392

No competing financial interests exist.

393

394

Figure Legends

395

Figure 1: A schematic flow diagram of the entire study.

396

397

Figure 2: Geographic location of targeted retail markets of this study.

398

For the largest scale: Star marking displays the location of Thai-Lao Friendship Bridge I; Blue and red dropped pins distribute the location of targeted Lao and Thai markets, respectively.

400

401

402

403

404

405

406

407

408

Figure 4: Dendrogram generated using UPGMA algorithms based on MLST profiles, including phenotypic characterization and the epidemiological meta data of Salmonella isolated in the Thai-Lao border area.

410

411

412 


\section{References}

420

421

422

423

424

425

426

427

428

429

430

431

432

433

434
Australian Embassy Thailand. (2011). The First Thai - Laos Friendship Bridge. Available at http://thailand.embassy.gov.au/bkok/FunRun_Bridge_History.html (accessed 31 July 2017).

Basler C, Nguyen T-A, Anderson TC, Hancock T, Behravesh CB. 2016. Outbreaks of Human Salmonella Infections Associated with Live Poultry, United States, 1990-2014. Emerging Infectious Diseases 22(10):1705-1711. DOI: 10.3201/eid2210.150765.

Boonmar S, Morita Y, Pulsrikarn C, Chaichana P, Pornruagwong S, Chaunchom S, Sychanh T, Khounsy T, Sisavath D, Yamamoto S, Sato H, Ishioka T, Noda M, Kozawa K, Kimura H. 2013. Salmonella prevalence in meat at retail markets in Pakse, Champasak Province, Laos, and antimicrobial susceptibility of isolates. Journal of Global Antimicrobial Resistance 1(3):157-161. DOI: 10.1016/j.jgar.2013.05.001.

Campioni F, Moratto Bergamini AM, Falcao JP. 2012. Genetic diversity, virulence genes and antimicrobial resistance of Salmonella Enteritidis isolated from food and humans over a 24-year period in Brazil. Food Microbiology 32(2):254-264. DOI: 10.1016/j.fm.2012.06.008. 
435 Clinical and Laboratory Standards Institute (CLSI). 2011. Performance standards for

436

437

438

439

440

441

442

443

444

445

446

447

448

449

450

451

452

453

454

455

456 antimicrobial disc susceptibility test; Approved standard-Tenth Edition. Wayne, PA:

Clinical and Laboratory Standards Institute.

Conlan JV, Vongxay K, Khamlome B, Gomez-Morales MA, Pozio E, Blacksell SD, Fenwick S, Thompson RCA. 2014. Patterns and Risks of Trichinella Infection in Humans and Pigs in Northern Laos. PLOS Neglected Tropical Diseases 8(7):e3034. DOI:

10.1371/journal.pntd.0003034.

Ferrari RG, Rosario DKA, Cunha-Neto A, Mano SB, Figueiredo EES, Conte-Junior CA. 2019. Worldwide Epidemiology of Salmonella Serovars in Animal-Based Foods: a Metaanalysis. Applied and Environmental Microbiology 85(14):e00591-00519. DOI: 10.1128/AEM.00591-19.

Foley SL, Lynne AM. 2008. Food animal-associated Salmonella challenges: pathogenicity and antimicrobial resistance. Journal of Animal Science 86(14):E173-187. DOI: 10.2527/jas.2007-0447.

Gomes-Neves E, Antunes P, Tavares A, Themudo P, Cardoso MF, Gartner F, Costa JM, Peixe L. 2012. Salmonella cross-contamination in swine abattoirs in Portugal: Carcasses, meat and meat handlers. International Journal of Food Microbiology 157(1):82-87. DOI: 10.1016/j.ijfoodmicro.2012.04.015.

Guardabassi L, Jensen LB, Kruse H. 2008. Guide to Antimicrobial Use in Animals. Oxford, UK: Blackwell Publishing Ltd.

Harbottle H, White DG, McDermott PF, Walker RD, Zhao S. 2006. Comparison of multilocus sequence typing, pulsed-field gel electrophoresis, and antimicrobial susceptibility typing 
457

458

459

460

461

462

463

464

465

466

467

468

469

470

471

472

473

474

475

476

477

478

for characterization of Salmonella enterica serotype Newport isolates. Journal of Clincal Microbiology 44(7):2449-2457. DOI: 10.1128/jcm.00019-06.

Hauser E, Hebner F, Tietze E, Helmuth R, Junker E, Prager R, Schroeter A, Rabsch W, Fruth A, Malorny B. 2011. Diversity of Salmonella enterica serovar Derby isolated from pig, pork and humans in Germany. International Journal of Food Microbiology 151(2):141-149. DOI: 10.1016/j.ijfoodmicro.2011.08.020.

Heyndrickx M, Vandekerchove D, Herman L, Rollier I, Grijspeerdt K, De Zutter L. 2002. Routes for salmonella contamination of poultry meat: epidemiological study from hatchery to slaughterhouse. Epidemiology and Infection 129(2):253-265. DOI: $10.1017 / \mathrm{s} 0950268802007380$.

Jajere SM. 2019. A review of Salmonella enterica with particular focus on the pathogenicity and virulence factors, host specificity and antimicrobial resistance including multidrug resistance. Veterinary World 12(4):504-521. DOI: 10.14202/vetworld.2019.504-521.

Kotetishvili M, Stine OC, Kreger A, Morris JG, Sulakvelidze A. 2002. Multilocus Sequence Typing for characterization of clinical and environmental Salmonella Strains. Journal of Clinical Microbiology 40(5):1626. DOI: 10.1128/JCM.40.5.1626-1635.2002.

Kurtz JR, Goggins JA, McLachlan JB. 2017. Salmonella infection: Interplay between the bacteria and host immune system. Immunology Letters 190:42-50. DOI: 10.1016/j.imlet.2017.07.006.

Liu WB, Liu B, Zhu XN, Yu SJ, Shi XM. 2011. Diversity of Salmonella isolates using serotyping and multilocus sequence typing. Food Microbiology 289(6):1182-1189. DOI: 10.1016/j.fm.2011.04.001. 
479 480 481 482 483 484 485 486 487

Lo Fo Wong DMA, Hald T, Van der Wolf P, Swanenburg M. 2002. Epidemiology and control measures for Salmonella in pigs and pork. Livestock Production Science 76:215-222. DOI: $10.1016 / \mathrm{S} 0301-6226(02) 00121-5$.

Mainali C, Gensler G, Mcfall M, King R, Irwin R, Senthilselvan A. 2009. Evaluation of Associations between Feed Withdrawal and Other Management Factors with Salmonella Contamination of Broiler Chickens at Slaughter in Alberta. Journal of Food Protection 72(10):2202-2207.

Mughini-Gras L, Enserink R, Friesema I, Heck M, van Duynhoven Y, van Pelt W. 2014. Risk factors for human salmonellosis originating from pigs, cattle, broiler chickens and egg laying hens: a combined case-control and source attribution analysis. PLoS One 9(2):e87933-e87933. DOI: 10.1371/journal.pone.0087933.

Muñoz-Ramirez ZY, Pascoe B, Mendez-Tenorio A, Mourkas E, Sandoval-Motta S, Perez-Perez G, Morgan DR, Dominguez RL, Ortiz-Princz D, Cavazza ME, Rocha G, Queiroz DMM, Catalano M, Palma GZ, Goldman CG, Venegas A, Alarcon T, Oleastro M, Vale FF, Goodman KJ, Torres RC, Berthenet E, Hitchings MD, Blaser MJ, Sheppard SK, Thorell K, Torres J. 2021. A 500-year tale of co-evolution, adaptation, and virulence: Helicobacter pylori in the Americas. The ISME Journal 15(1):78-92. DOI: 10.1038/s41396-020-00758-0.

Napasirth P, Napasirth V. 2018. Current situation and future prospects for beef production in Lao People's Democratic Republic - A review. Asian-Australasian Journal of Animal Sciences 31(7):961-967. DOI: 10.5713/ajas.18.0206.

Okello AL, Tiemann TT, Inthavong P, Khamlome B, Phengvilaysouk A, Keonouchanh S, Keokhamphet C, Somoulay V, Blaszak K, Blacksell SD, Okello WO, Allen J. 2017. 
502

503

504

505

506

507

508

509

510

511

512

513

514

515

516

517

518

519

520

521

522

523

524

Integrating market chain assessments with zoonoses risk analysis in two cross-border pig value chains in Lao PDR. Asian-Australasian Journal of Animal Sciences 30(11):16511659. DOI: 10.5713 /ajas. 16.0887

Padungtod P, Kaneene JB. 2006. Salmonella in food animals and humans in northern Thailand. International Journal of Food Microbiology 108(3):346-354. DOI: 10.1016/j.ijfoodmicro.2005.11.020.

Patchanee P, Eiamsam-Ang T, Vanaseang J, Boonkhot P, Tadee P. 2017. Determination of regional relationships among Salmonella spp. isolated from retail pork circulating in the Chiang Mai municipality area using a WGS data approach. International Journal of Food Microbiology 254:18-24. DOI: 10.1016/j.ijfoodmicro.2017.05.006.

Patchanee P, Tansiricharoenkul K, Buawiratlert T, Wiratsudakul A, Angchokchatchawal K, Yamsakul P, Yano T, Boonkhot P, Rojanasatien S, Tadee P. 2016. Salmonella in pork retail outlets and dissemination of its pulsotypes through pig production chain in Chiang Mai and surrounding areas, Thailand. Preventive Veterinary Medicine 130:99-105. DOI: 10.1016/j.prevetmed.2016.06.013.

Phongaran D, Khang-Air S, Angkititrakul S. 2019. Molecular epidemiology and antimicrobial resistance of Salmonella isolates from broilers and pigs in Thailand. Veterinary World 12(8):1311-1318. DOI: 10.14202/vetworld.2019.1311-1318.

Popoff MY, Bockemühl J, McWhorter-Murlin A. 1993. Supplement 1992 (no. 36) to the Kauffmann-White scheme. Research in Microbiology 144(6):495-498. DOI: doi.org/10.1016/0923-2508(93)90058-A.

Pulsrikarn C, Chaichana P, Pornruangwong S, Morita Y, Yamamoto S, Boonmar S. 2012. Serotype, Antimicrobial Susceptibility, and Genotype of Salmonella Isolates from Swine 

42(1):21-28.

527

528

529

530

531

532

533

534

535

536

537

538

539

540

541

542

543

544

545

546

547

Rostagno MH, Callaway TR. 2012. Pre-harvest risk factors for Salmonella enterica in pork production. Food Research International 45(2):634-640. DOI: 10.1016/j.foodres.2011.04.041.

Shang K, Wei B, Kang M. 2018. Distribution and dissemination of antimicrobial-resistant Salmonella in broiler farms with or without enrofloxacin use. BMC Veterinary Research 14(1):257. DOI: 10.1186/s12917-018-1590-1.

Sinwat N, Angkittitrakul S, Coulson KF, Pilapil FM, Meunsene D, Chuanchuen R. 2016. High prevalence and molecular characteristics of multidrug-resistant Salmonella in pigs, pork and humans in Thailand and Laos provinces. Journal of Medical Microbiology 65(10):1182-1193. DOI: 10.1099/jmm.0.000339.

Sirichote P, Bangtrakulnonth A, Tianmanee K, Unahalekhaka A, Oulai A, Chittaphithakchai P, Kheowrod W, Hendriksen RS. 2010. Serotypes and Antimicrobial Resistance of Salmonella enterica ssp in Central Thailand, 2001-2006. The Southeast Asian journal of tropical medicine and public health 41(6):1405-1415.

Trongjit S, Angkititrakul S, Tuttle R, Poungseree J, Padungtod P, Chuanchuen R. 2017. Prevalence and antimicrobial resistance in Salmonella enterica isolated from broiler chickens, pigs and meat products in the Thailand-Cambodia border provinces: AMR in Salmonella enterica. Microbiology and Immunology 61. DOI: 10.1111/1348-0421.12462.

University of Warwick. EnteroBase: Salmonella enterica MLST Database. Available at http://enterobase.warwick.ac.uk/species/senterica/allele_st_search (accessed 22 June 2020). 
548 University of Zaragoza. Win Epi: Sample size: Estimate Percentage. Available at

549 http://www.winepi.net/uk/index.htm (accessed on 21 December 2018).

550 Van Boxstael S, Dierick K, Van Huffel X, Uyttendaele M, Berkvens D, Herman L, Bertrand S,

551 Wildemauwe C, Catry B, Butaye P, Imberechts H. 2012. Comparison of antimicrobial

552

553

554

555

556

557

558

559

560

561

562

563

564

565

566

567

568

569

570

Yang Y, Ashworth AJ, Willett C, Cook K, Upadhyay A, Owens PR, Ricke SC, DeBruyn JM, Moore Jr. PA. 2019. Review of Antibiotic Resistance, Ecology, Dissemination, and Mitigation in U.S. Broiler Poultry Systems. Frontiers in Microbiology 10:e2639. DOI: 10.3389/fmicb.2019.02639.

Zhou Z, Alikhan NF, Mohamed K, Fan Y, Agama Study Group, Achtman, M. 2020. The EnteroBase user's guide, with case studies on Salmonella transmissions, Yersinia pestis phylogeny, and Escherichia core genomic diversity. Genome research 30(1):138152. DOI: $10.1101 /$ gr.251678.119. 
Figure 1

A schematic flow diagram of the entire study

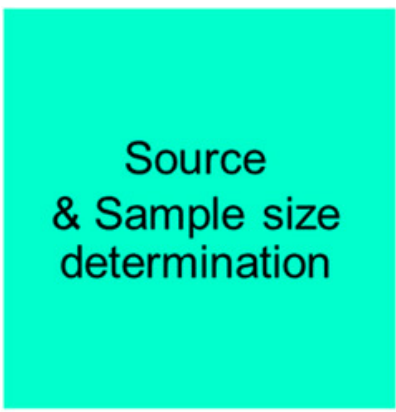

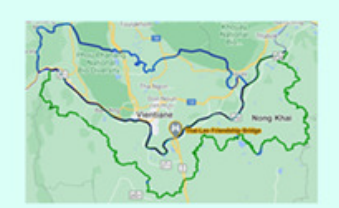

Unit of interest

Meat sold in Thai-Lao border area

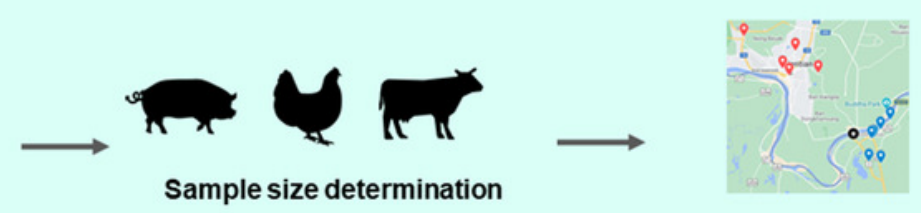

Minimum of $121,105 \& 79$ of pork, chicken $\&$ beef were designated

Targeted the marketplaces 5 in Lao PDR / 6 in Thailand

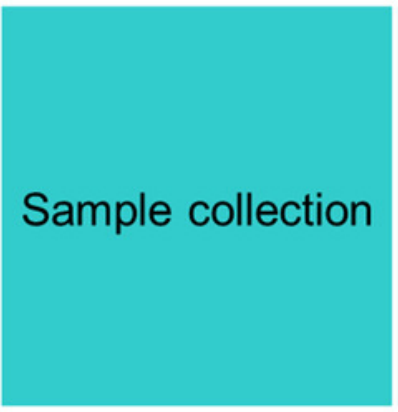

Laboratory

Procedure

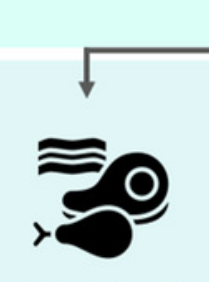

Sample collection

$121,135 \& 116$ of pork, chicken \&

beef were collected

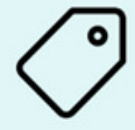

Individually label

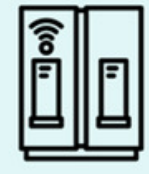

Packing \& Refrigerated storage

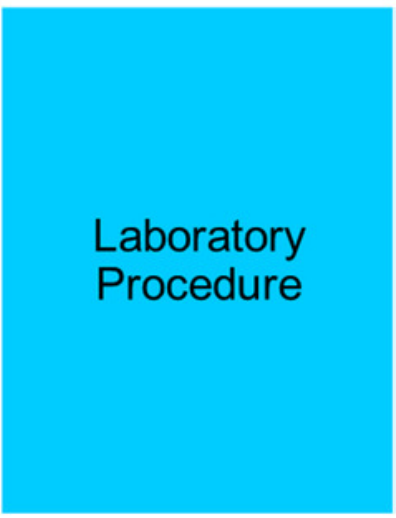

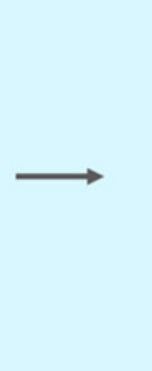

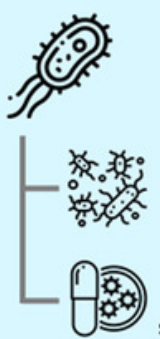

All positive samples Serotyping

Antimicrobial susceptibility test

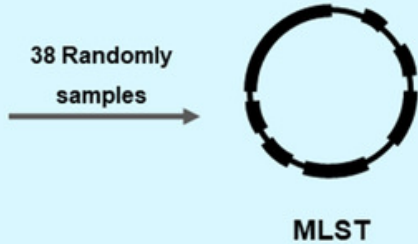




\section{Figure 2}

Geographic location of targeted retail markets of this study.

For the largest scale: Star marking displays the location of Thai-Lao Friendship Bridge I; Blue and red dropped pins distribute the location of targeted Lao and Thai markets, respectively.

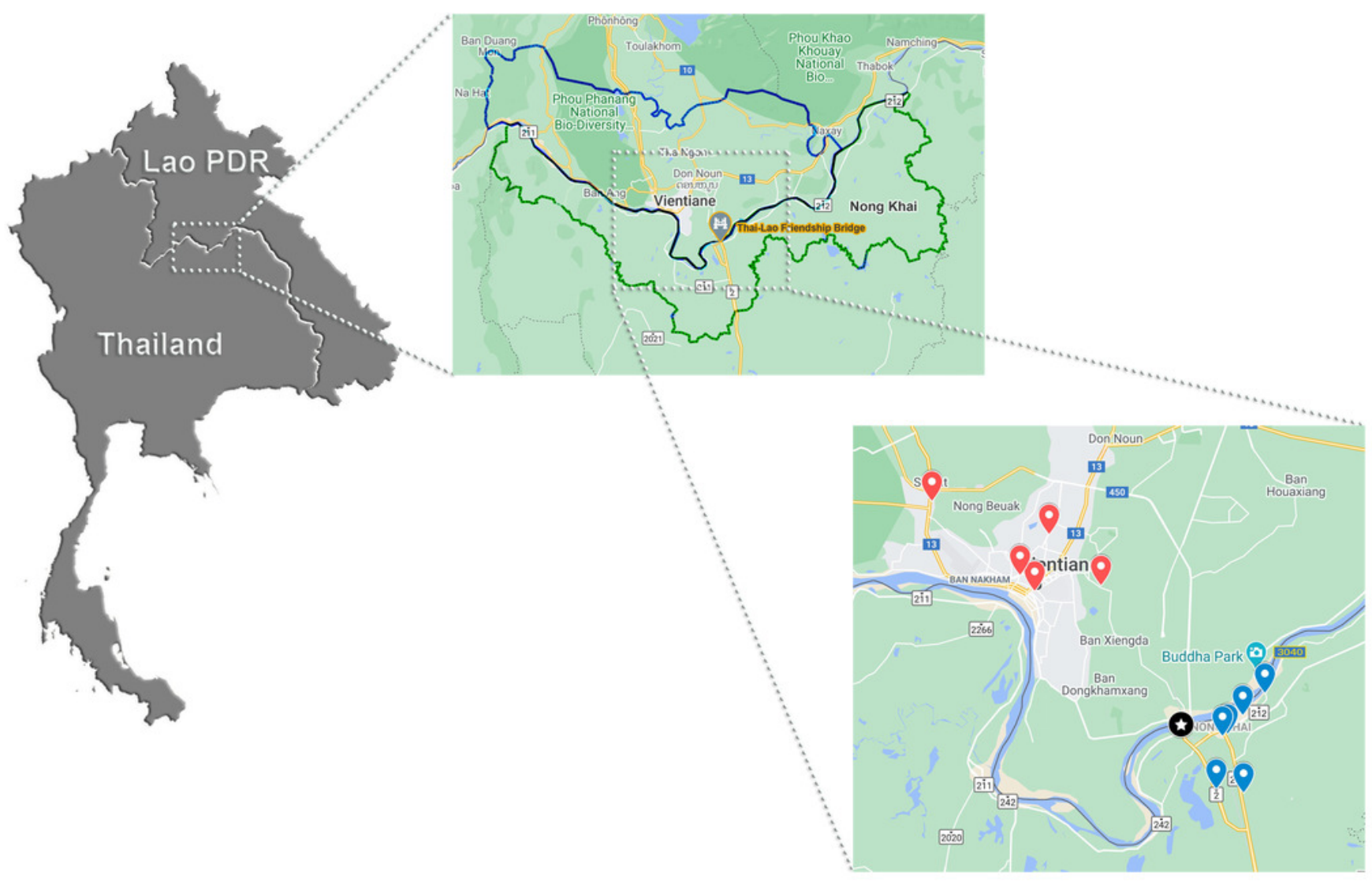


Figure 3

Rate of resistance (\%) to selected antimicrobials in Salmonella isolated from various meat products in the Thai-Lao border area .

Antibiotic abbreviations: amoxicillin-clavulanic acid (AMC); ampicillin (AMP); chloramphenicol

(C); ciprofloxacin (CIP); cefotaxime (CTX); nalidixic acid (NA); norfloxacin (NOR);

sulfamethoxazole-Trimethoprim (SXT); streptomycin (S); tetracycline (TE).

Thailand

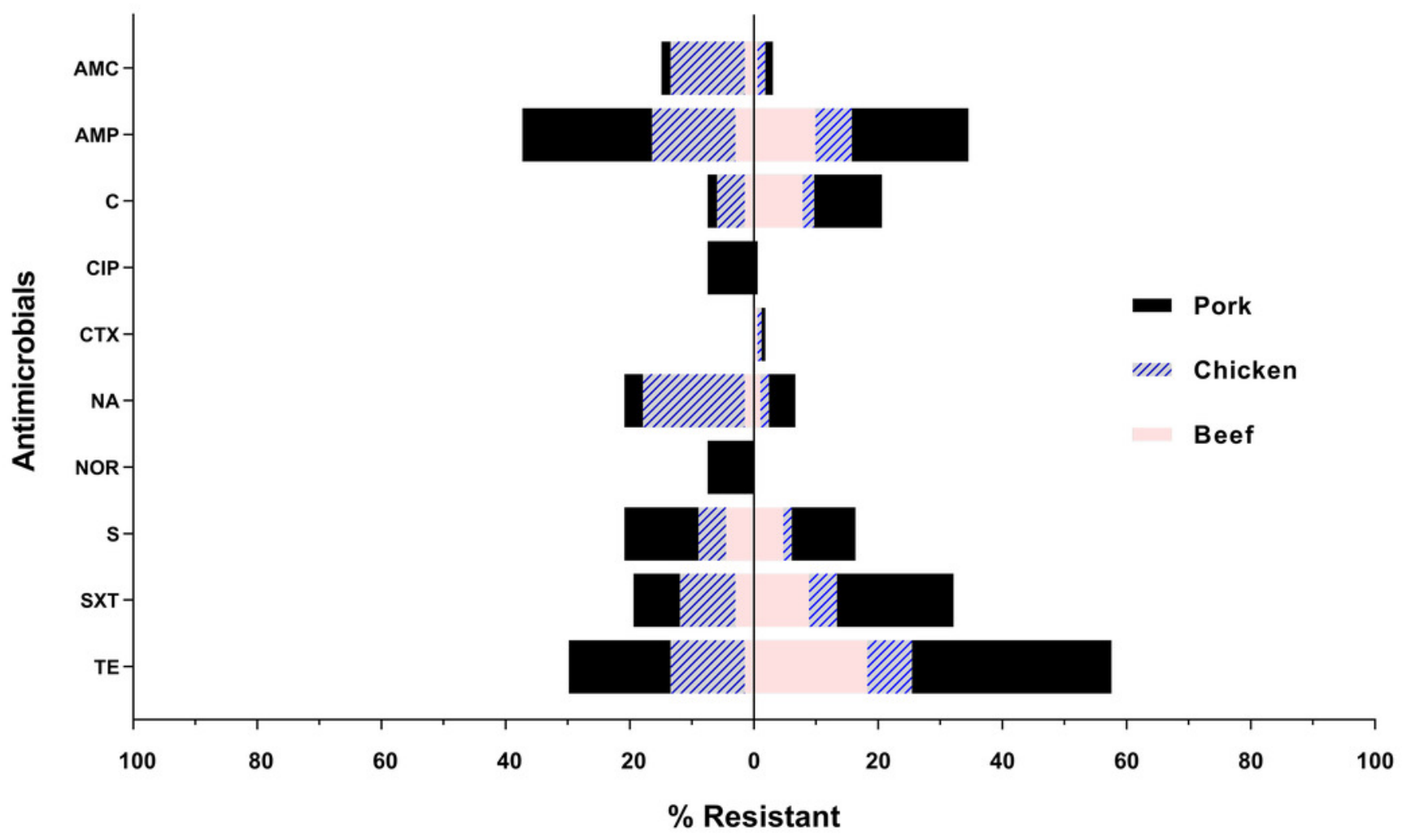


Figure 4

\section{Dendrogram generated using UPGMA algorithms based on MLST profiles, including phenotypic characterization and the epidemiological meta data of Salmonella isolated in} the Thai-Lao border area.

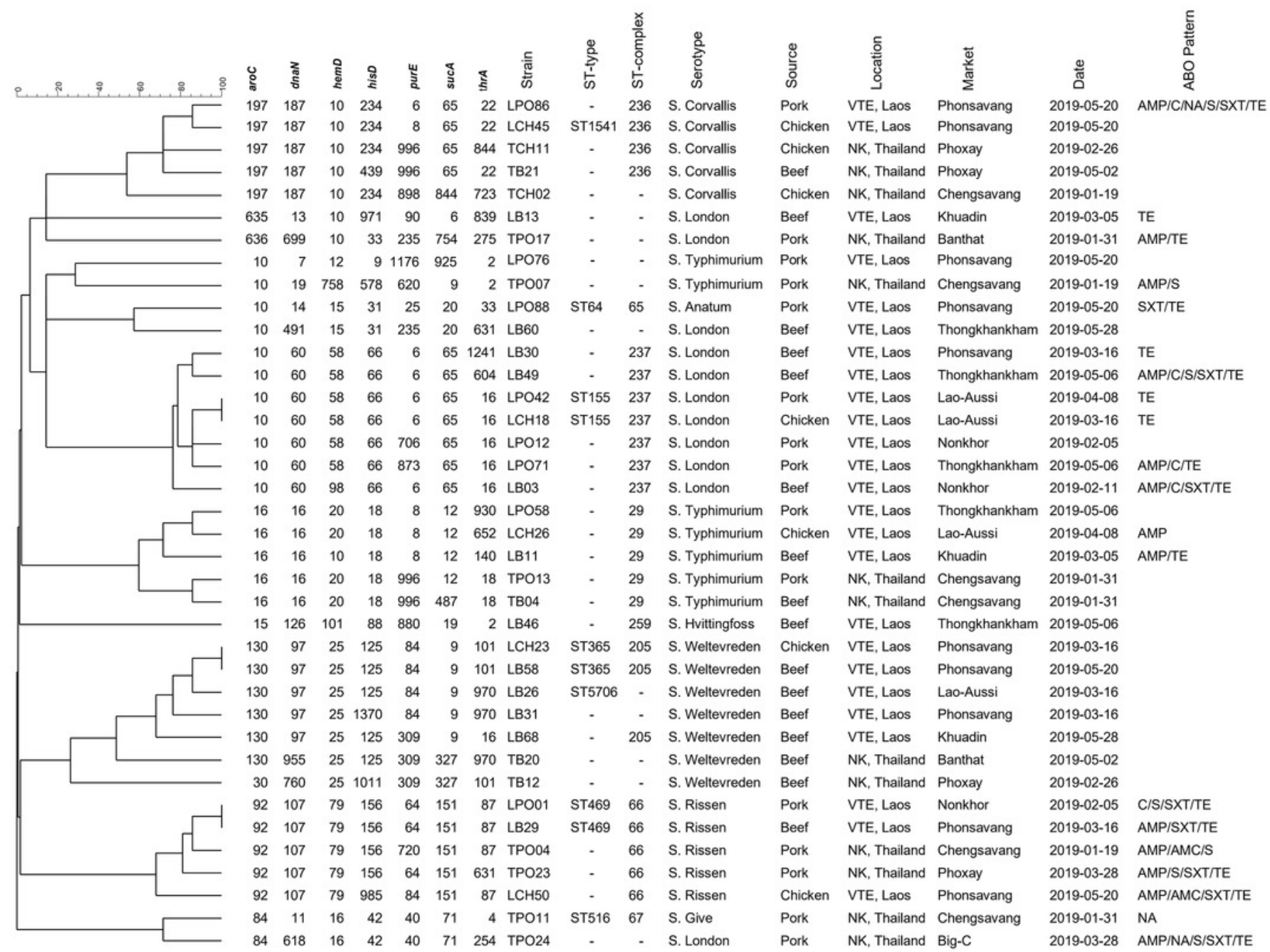




\section{Table $\mathbf{1}$ (on next page)}

Distribution of prevalence and a $95 \%$ confidence interval of Salmonella isolated from various meat types in the Thai-Lao border area 
1 Table 1 Distribution of prevalence and a 95\% confidence interval of Salmonella isolated from

2 various meat types in the Thai-Lao border area.

3

\begin{tabular}{cccc}
\hline \multirow{2}{*}{ Type } & \multicolumn{2}{c}{ Location } & \\
\cline { 2 - 3 } & Thailand & Laos PDR & TOTAL \\
\hline \multirow{2}{*}{ Pork } & $18 / 28$ & $70 / 93$ & $88 / 121^{\mathrm{A}}$ \\
& $(64.29 ; 44.07-81.36 \%)$ & $(75.27 ; 65.24-83.63 \%)$ & $(72.73 ; 63.88-80.43 \%)$ \\
Chicken & $31 / 66$ & $43 / 67$ & $74 / 133^{\mathrm{B}}$ \\
& $(46.97 ; 34.56-59.66 \%)$ & $(64.18 ; 51.53-75.53 \%)$ & $(55.64 ; 46.78-64.25 \%)$ \\
Beef & $18 / 41$ & $52 / 75$ & $70 / 116^{\mathrm{AB}}$ \\
& $(43.90 ; 28.47-60.25 \%)$ & $(69.33 ; 57.62-79.47 \%)$ & $(60.34 ; 50.84-69.31 \%)$ \\
TOTAL & $67 / 135^{\mathrm{a}}$ & $165 / 235^{\mathrm{b}}$ & $232 / 370$ \\
& $(49.63 ; 40.92-58.36 \%)$ & $(70.21 ; 63.92-75.98 \%)$ & $(62.70 ; 57.67-67.48 \%)$ \\
\hline
\end{tabular}

4

5 Use of fisher's exact analysis and difference of superscript (A, B) indicate significant differences

$6(p<0.05)$ of prevalence detected among meat types. Difference of superscript $(a, b)$ indicates

7 significant differences $(\mathrm{p}<0.05)$ of prevalence detected among all locations.

8 


\section{Table 2 (on next page)}

Sero-distribution of Salmonella isolated from various meat types at the Thai-Lao border area. 
1 Table 2 Sero-distribution of Salmonella isolated from various meat types at the Thai-Lao border

2 area.

\begin{tabular}{|c|c|c|c|c|c|c|c|c|}
\hline \multirow{2}{*}{ Salmonella serotype } & \multicolumn{3}{|c|}{ Nong Khai, Thailand } & \multicolumn{3}{|c|}{ Vientiane, Laos PDR } & \multicolumn{2}{|c|}{ Total } \\
\hline & Pork & Chicken & Beef & Pork & Chicken & Beef & $\mathbf{n}$ & $\%$ \\
\hline S. Agona & & & & & 2 & & 2 & 0.86 \\
\hline S. Albany & & 1 & & & & & 1 & 0.43 \\
\hline S. Altona & & & & 2 & & & 2 & 0.86 \\
\hline S. Amsterdam & & & & 2 & & 1 & 3 & 1.29 \\
\hline S. Anatum & 3 & & & 2 & & & 5 & 2.16 \\
\hline S. Bareilly & & 3 & & & & & 3 & 1.29 \\
\hline$S$. Bovismorbificans & & & 2 & & & & 2 & 0.86 \\
\hline S. Brimingham & & & & 1 & & & 1 & 0.43 \\
\hline$S$. Brunei & & 1 & & & 1 & 3 & 5 & 2.16 \\
\hline S. Cerro & & & 1 & & & & 1 & 0.43 \\
\hline S. Corvallis & & 8 & 1 & 4 & 19 & & 32 & 13.79 \\
\hline S. Duesseldorf & & 1 & & & & & 1 & 0.43 \\
\hline$S$. Eastbournc & & & 2 & & & & 2 & 0.86 \\
\hline$S$. Elisabethville & & & & & & 1 & 1 & 0.43 \\
\hline$S$. Enteritidis & & 1 & & & & & 1 & 0.43 \\
\hline S. Farehan & & & 1 & & & & 1 & 0.43 \\
\hline$S$. Farsta & & & & & 1 & & 1 & 0.43 \\
\hline$S$. Fulda & & & 1 & & & 1 & 2 & 0.86 \\
\hline S. Gabon & & & & & 1 & & 1 & 0.43 \\
\hline S. Give & 1 & & & 4 & & & 5 & 2.16 \\
\hline S. Goma & & & & 1 & & & 1 & 0.43 \\
\hline S. Havana & & & & 2 & & & 2 & 0.86 \\
\hline S. Hvittingfoss & & 2 & & 2 & & 1 & 5 & 2.16 \\
\hline$S$. Itami & & & & & 2 & & 2 & 0.86 \\
\hline
\end{tabular}




\begin{tabular}{|c|c|c|c|c|c|c|c|c|}
\hline$S$. Jerusalem & 1 & & & & & & 1 & 0.43 \\
\hline S. Kapemba & & & & & 1 & & 1 & 0.43 \\
\hline$S$. Kedougou & & & & 8 & 1 & & 9 & 3.88 \\
\hline S. Kikoma & & & & & & 1 & 1 & 0.43 \\
\hline$S$. Kortrijk & & 1 & & & & & 1 & 0.43 \\
\hline S. Lexington & & & 1 & & & & 1 & 0.43 \\
\hline$S$. Livingstone & & & & & 1 & & 1 & 0.43 \\
\hline S. Lomita & & & & & 1 & & 1 & 0.43 \\
\hline$S$. London & 2 & & & 32 & 1 & 26 & 61 & 26.99 \\
\hline S. Mbandaka & & 2 & & & 1 & & 3 & 1.29 \\
\hline$S$. Meleagridis & & & 1 & 3 & & & 4 & 1.72 \\
\hline S. Mikamasima & 1 & & & & & & 1 & 0.43 \\
\hline$S$. Monschui & & & & & 3 & & 3 & 1.29 \\
\hline$S$. Montevideo & & & & & & 1 & 1 & 0.43 \\
\hline$S$. Muenster & 1 & & & & & 1 & 2 & 0.86 \\
\hline$S$. Newport & & 2 & & 1 & & & 3 & 1.29 \\
\hline S. Ordonez & & 4 & & & & & 4 & 1.72 \\
\hline S. Planckendael & & & & 1 & & & 1 & 0.43 \\
\hline$S$. Regent & & & & & 1 & & 1 & 0.43 \\
\hline$S$. Rissen & 5 & & & 3 & 3 & 4 & 15 & 6.47 \\
\hline S. Ruzizi & & & 1 & & & & 1 & 0.43 \\
\hline S. Saintpaul & & 2 & & & & & 2 & 0.86 \\
\hline$S$. Sangera & & & & & & 2 & 2 & 0.86 \\
\hline S. Stanley & & 1 & & 1 & & & 2 & 0.86 \\
\hline S. Stanleyville & & 1 & & & & & 1 & 0.43 \\
\hline$S$. Typhimurium & 3 & & 1 & 2 & 3 & 2 & 11 & 4.74 \\
\hline S. Uganda & & 1 & & & & & 1 & 0.43 \\
\hline S. Wagenia & & & & & & 1 & 1 & 0.43 \\
\hline S. Weltevreden & & & 6 & & 1 & 7 & 14 & 6.03 \\
\hline Total & 18 & 31 & 18 & 70 & 43 & 52 & 232 & 100.00 \\
\hline
\end{tabular}




\section{Table 3(on next page)}

Variation of housekeeping genes loci of un-identified Sequence Type (ST) Salmonella strains circulating in the Thai-Lao border area. 
1 Table 3 Variation of housekeeping genes loci of un-identified Sequence Type (ST) Salmonella

2 strains circulating in the Thai-Lao border area.

\begin{tabular}{|c|c|c|c|c|c|c|c|c|}
\hline \multirow[t]{2}{*}{ Strain } & \multirow{2}{*}{$\begin{array}{c}\text { Most } \\
\text { related } \mathbf{S T}^{\mathrm{a}}\end{array}$} & \multicolumn{7}{|c|}{7 Housekeeping gene for MLST $^{b}$} \\
\hline & & aro $\mathrm{C}$ & $d n a \mathrm{~N}$ & hem $\mathrm{D}$ & his $\mathrm{D}$ & purE & sucA & $t h r \mathrm{~A}$ \\
\hline LPO12 & ST155 & 10 & 60 & 58 & 66 & $6 \rightarrow 706$ & 65 & 16 \\
\hline LPO58 & ST29 & 16 & 16 & 20 & 18 & 8 & 12 & $18 \rightarrow 930$ \\
\hline LPO71 & ST155 & 10 & 60 & 58 & 66 & $6 \rightarrow 873$ & 65 & 16 \\
\hline LPO76 & ST7498 & 10 & 7 & 12 & 9 & 1176 & $9 \rightarrow 925$ & 2 \\
\hline LPO86 & ST1541 & 197 & 187 & 10 & 234 & $8 \rightarrow 6$ & 65 & 22 \\
\hline LCH26 & ST29 & 16 & 16 & 20 & 18 & 8 & 12 & $18 \rightarrow 652$ \\
\hline LCH50 & ST469 & 92 & 107 & 79 & $156 \rightarrow 985$ & $64 \rightarrow 84$ & 151 & 87 \\
\hline LB03 & ST155 & 10 & 60 & $58 \rightarrow 98$ & 66 & 6 & 65 & 16 \\
\hline LB11 & ST29 & 16 & 16 & $20 \rightarrow 10$ & 18 & 8 & 12 & $18 \rightarrow 140$ \\
\hline LB13 & ST1799 & $202 \rightarrow 635$ & $4 \rightarrow 13$ & 10 & $33 \rightarrow 971$ & 90 & 6 & $275 \rightarrow 839$ \\
\hline LB30 & ST155 & 10 & 60 & 58 & 66 & 6 & 65 & $16 \rightarrow 1241$ \\
\hline LB31 & ST5706 & 130 & 97 & 25 & $125 \rightarrow 1370$ & 84 & 9 & 970 \\
\hline LB46 & ST446 & 15 & 126 & 101 & 88 & $8 \rightarrow 880$ & 19 & $18-2$ \\
\hline LB49 & ST155 & 10 & 60 & 58 & 66 & 6 & 65 & $16 \rightarrow 604$ \\
\hline LB60 & ST64 & 10 & $14 \rightarrow 491$ & 15 & 31 & $25 \rightarrow 235$ & 20 & $33 \rightarrow 631$ \\
\hline LB68 & ST365 & 130 & 97 & 25 & 125 & $84 \rightarrow 309$ & 9 & 16 \\
\hline TPO04 & ST469 & 92 & 107 & 79 & 156 & $64 \rightarrow 720$ & 151 & 87 \\
\hline ТРO07 & ST34 & 10 & 19 & $12 \rightarrow 758$ & $9 \rightarrow 578$ & $5 \rightarrow 620$ & 9 & 2 \\
\hline ТPO13 & ST29 & 16 & 16 & 20 & 18 & $8 \rightarrow 996$ & 12 & 18 \\
\hline TPO17 & ST3157 & 636 & $4 \rightarrow 699$ & 10 & 33 & $90 \rightarrow 235$ & $6 \rightarrow 754$ & 275 \\
\hline TPO23 & ST469 & 92 & 107 & 79 & 156 & 64 & 151 & $87 \rightarrow 631$ \\
\hline TPO24 & ST616 & 84 & $11 \rightarrow 618$ & 16 & 42 & 40 & 71 & $4 \rightarrow 254$ \\
\hline TCH02 & ST197 & 197 & 187 & 10 & 234 & $8 \rightarrow 898$ & 844 & $22 \rightarrow 723$ \\
\hline TCH11 & ST1541 & 197 & 187 & 10 & 234 & $8 \rightarrow 996$ & 65 & $22 \rightarrow 844$ \\
\hline TB04 & ST29 & 16 & 16 & 20 & 18 & $8 \rightarrow 996$ & $12 \rightarrow 487$ & 18 \\
\hline TB12 & ST283 & $101 \rightarrow 30$ & $97 \rightarrow 760$ & 25 & $86 \rightarrow 1011$ & $101 \rightarrow 309$ & $19 \rightarrow 327$ & 101 \\
\hline TB20 & ST5706 & 130 & $97 \rightarrow 955$ & 25 & 125 & 84-309 & $9 \rightarrow 327$ & 970 \\
\hline TB21 & ST1541 & 197 & 187 & 10 & $234 \rightarrow 439$ & $8 \rightarrow 996$ & 65 & 22 \\
\hline
\end{tabular}




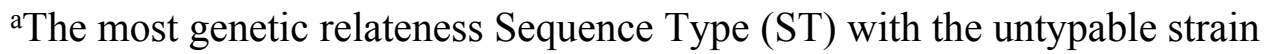

${ }^{b}$ Variation of the housekeeping genes alleic number from known ST to untyable ST 